\title{
A INTERSUBJETIVIDADE EM HUSSERL E EM LEVINAS
}

Marcelo Luis Pelizzoli*

\begin{abstract}
SINTESE - A intersubjetividade em Husserl é marcada pela objetividade, pela imanência da intencionalidade implicativa e pelo idealismo do cogito. Levinas contrapõe a isto um modo de relação com transitividade e transcendência diversa, pela qual se supere o horizonte de adequação fenomenal da alteridade e onde o "outro não seja reduzido ao mesmo".

ABSTRACT - The intersubjectivity in Husserl is marked by the immanence of the implicative intencionality and by the idealism of the cogito. Levinas counterpoints to this a mode of relation with transitivity and diverse trancendence, by means of which the horizon of phenomenological adequation of the alterity is surpassed, and where "the other is not reduced to the same".
\end{abstract}

\section{Introdução}

Para a análise desta temática situamo-nos a partir do contexto de duas obras fundamentais: primeiramente, as Meditações Cartesianas (1913), de E. Husserl, ainda no auge de seu pensamento idealista-transcendental. É o lugar onde aparece pela primeira vez uma preocupação efetiva com a questão da alteridade - na $\mathrm{V}$ Meditação - que vem pôr à prova o projeto de uma filosofia rigorosa e determinada pela transcendentalidade interna do ego cogito. Em segundo lugar, em E. Levinas, refletimos não mais além de Totalidade e Infinito (1961), onde vemos, entre outras coisas, uma reflexão orientada pela diferença entre objetividade e transcendência, consciência e alteridade, Mesmo e Outro, o que guiará nossa exposição da relação ao outro. Analisamos como o outro entra no projeto egológico husserliano e como ele deve ser visto para que seja resguardada sua alteridade, no caso de Levinas. Não estamos a apontar a posição de Levinas como a superação completa da análise da intersubjetividade, e como a verdadeira filosofia para a alteridade. Refletimos, em sintese, sob dois modelos de relação ao outro: $01^{\circ}$ tem em vista uma fundamentação segura e apodítica para toda filosofia e ciência, ou seja, a questão primordial diz respeito à objetividade a ser alcançada pelo eu que conhece as realidades e os outros. Já no $2^{\circ}$ modelo, temos a apresentação da relação em vista de um comércio eminentemente empírico-ético, que quer ultrapassar a fenomenalidade, o objetivismo e o idealismo do eu transcendental. Procuramos evidenciar assim a diferença e a interação crítica entre a abordagem da intersubjetividade no nível da

* Professor da Fundação Universidade de Rio Grande - FURG.

\begin{tabular}{|l|l|l|l|l|l|}
\hline VERITAS & Porto Alegre & v. 41 & $\mathrm{n}^{2} 161$ & Março 1996 & p. 47-55 \\
\hline
\end{tabular}


subjetividade do cogito em sla auto-reflexividade, e a abordagem no âmbito da transcendência e exterioridade como prática ética - que vai da subjetividade, como viver e sensibilidade, antecedendo o cogito, até o espaço do ultrapassamento, Desejo do Outro como Rosto (visage). ${ }^{1}$ As críticas a Husserl, e a qualquer filosofia, são cabiveis na medida em que se reflete muito hoje sobre a "periculosidade" da razão (e sobre o fato do "saber como poder"), sobre a interação entre teoria do conhecimento e ética, saber e vida... Não obstante, a crítica que apresentamos não é à descoberta da intencionalidade como tal, à razão ou método fenomenológico em si, mas antes ao privilégio e ao alcance de sua lógica diante do outro como outro, ao abarcamento do sentido.

\section{1 - Subjetividade transcendental e solipsismo}

Comecemos, então, abordando os prolegômenos necessários ao entendimento da objeção do solipsismo frente ao ego cogito e do aparecimento da questão da intersubjetividade em Husserl.

Contextualizando, é nas $M C$ (Meditações Cartesianas) que o último grande idealista transcendental percorre, mais uma vez, o anseio iniciado com Descartes ao elaborar a idéia de um fundamento absoluto do conhecimento a partir do sujeito pensante e da consciência de si mesmo. Isto em vista de uma objetividade absolutamente cônscia e segura de seus axiomas; base para toda ciência. Este ponto de partida invariável, apodítico e seguro, será o eu transcendental, centro e domínio original de consciência. Mas para alcançar este fundante indubitável é preciso um método que o revele como tal, como constituinte originário de todo conhecimento. A epoqué irá delimitar, então, na subjetividade, o próprio conhecimento - o transcendental - separando-o dos estados mundanos, da tese natural, das relações cotidianas, do mundo e dos outros. Retorna-se ao núcleo primeiro de toda percepção e experiência; abstraindo-se de toda crença no mundo encaminha-se uma filosofia da consciência, uma meditação sobre as possibilidades últimas da razão e sua essência, numa verdadeira "egologia" (cf. $M C$ 25-26). Tal poder de redução, que perfaz um modo privilegiado e esclarecido de existência, é possível pela descoberta da atividade de prestar sentido a todo real, ato proporcionado como consciência, a qual é sempre intencional. Ou seja, naturalmente, ela visa e direciona o sentido da realidade, não porque encontra o objeto "real" em si, nem porque constrói uma representação e idéia deste objeto, mas porque, antes disso, ela é já doadora de sentido pelo fato de ser consciência; é pelo seu fluxo de vividos que se elabora toda presença. A consciência possui agora, idealmente, o mundo em seu ato, como fenômeno, pensado enquanto minha reconstrução, como o que me aparece. Reposiciona portanto o sujeito como verdadeiro construtor (constituinte) de todo sentido da realidade; abre a esfera na qual toda transcendência resolve-se na imanência, $\mathrm{e}$ soluciona assim a questão do conhecimento fazendo com que o "em si" seja "para mim". Ou seja, a consciência intencional perfaz uma interligação e dependência radical entre o seu "consciência de... (outra coisa que não ela mesma) - que seria a transcendência - e o sentido prestado e engendrado pelo ego cogito, que evoca a imanência (todo sentido deve passar pelo cogito, pela formatação do entendimento;

1 Há duas traduçōes para visage: rosto ou olhar. 
o externo mistura-se com o interno; há uma inclusão intencional do mundo na consciência)".2

Por conseguinte, o eu cognoscente recebe papel central e autônomo - "faz suas próprias leis" - inferindo, através da epoqué, toda realidade a partir da - ou como - consciência, reunindo a multiplicidade numa totalidade ou conjunto ordenado (cf. $M C$ 22) num sistema orgânico universal. E o eu como mônada, a qual responde pelo universo possível em sua interioridade. Com a atitude fenomenológica, a subjetividade afasta-se do mundano e de sua relações para almejar, no âmbito soIus ipse do sujeito transcendental absoluto, a constituição do mundo e seu sentido, a partir das leis a priori das vivências intencionais. A atitude fenomenológica é, pois, um dinamismo da subjetividade, a qual se mostra ativa, livre e soberana. Destarte, surge então a objeção do solipsismo, que diz que o eu não se relacionaria de fato com o outro. Nada ultrapassa o cogito; estamos diante de uma ciência "absolutamente subjetiva" (cf. MC 25), em que sobra o resíduo absoluto e necessário, o "fenômeno" do ego cogito. O eu está enclausurado em sua auto-reflexividade e autonormatividade, ele guarda e determina todo sentido pelo crivo da autoconsciência, do eu puro.

$\mathrm{Na}$ medida em que ponho entre parêntesis o mundo "objetivo" e os outros, a vida subjetiva resta somente minha vida; já a razão e a verdade devem ser intersubjetivas, pois são vinculantes. Como conciliar? Ou seja, o projeto da ciência egológica está num impasse diante da questão da relação ao outro. Mas tal posição, onde todo existente parece ser "um simples momento de meu ser transcendental", seria, segundo Husserl, apenas metódica; a egologia depende da constituição de um mundo comum e da objetividade, as quais dependem da intersubjetividade.

\section{1 - Intersubjetividade transcendental}

A V Meditação vem ampliar as bases do ego arqui-fundamento a priori e original. Vemos que a premissa da constituição de todo sentido na corrente de vivências intencionais, na esfera do ego, não é abandonada. O outro é, tal como os objetos, ainda constituído - mas como "estranho", como outro - a partir do que me é próprio e "dado no original". O outro manifesta-se assim "sobre o fundo do nosso eu transcenclental" (MC 75). O outro não pode ficar fora dos parêntesis - como o mundo - que cerram o resíduo da redução; apenas no eu ele tem valor existencial (cf. MC 109). Mas para que a experiência transcendental do eu e do outro não se confundam será preciso uma "nova" redução (epoqué), que evidencie uma intencionalidade intersubjetiva, vinculante e implicativa. Redução no mais profundo do ego, que reflita o que é próprio de cada um (eu e outro). Abstraindo de todo o

2 Sob esta nova atitude existencial, e sintetizando, unificando a multiplicidade e identificando o que é trazido pelo poder da Iedução e da intenção, está o eu transcendental, do conhecimento; eu puro, mas com seu dominio de vivências, como raiz das essências, das significaçōes intencionais. E o ego, e mais profundamente o eidos ego, que faz (é) a unidade, a sintese constitutiva universal no próprio, no único, no mesmo (cf. $M C 22$ ). É este ego puro e central que condicionará a ipseidade os habitus, personalidade - da subjetividade concreta; todas as significações remetem a ele, substrato e pólo idêntico revelado como evidente, absoluto, único, a priori e essencial. Ego que confere e garante identidade a si próprio em meio às alterações por que passa: eu que está "acima das variações de si mesmon (MC 60). 
constituído, de todas as pertenças, de toda "produção" do ego, é aventado um domínio original, purissimo e primordial; uma "Natureza que me é própria". Partindo daí poderei constatar uma intencionalidade constituinte dos outros, os quais não são dados na contingência do mundo e das relações, mas dependem da redução ao próprio e original do cogito. Ou seja, os outros são outros porque espelhados no mais profundo do eu, são como eu, participam da minha natureza, diferentemente dos objetos. Daí o outro como alter ego. Delimitando-se a esfera do próprio, é possível, por analogia, constituir a idéia de uma "experiência de um outro que eu" (cf. $M C$ 79-80). Portanto, uma mesma intencionalidade concilia o sentido existencial novo, que "transgride o ser do meu próprio ego monádico", com o ego, ou seja, o outro é apreendido como reflexo de minha natureza. O outro é meu analogon e, contudo, deve ser constituído em mim como estranho (cf. MC 78).

Mais propriamente, como isso funcionará em termos de percepção que tenho de outrem? Para Husserl, a percepção de outrem tem uma ínfima diferenciação, ela é bipartida. Por aquela mesma intencionalidade o outro aparece à camada primordial do ego de forma mediata, por analogia, por um ato de co-apresentação (apprésentation) (cf. $M C$ 92). Este ato é interligado e depende de um ato pelo qual penso a mim como ego, no meu domínio puro em que as coisas são dadas a mim imediatamente, no original; domínio que Husserl chama de apresentação (présentation). Ou seja, o outro é alter pela co-presentação, e ego porque "participa" da apresentação de mim a mim mesmo, é como eu sou, igual em natureza, também constituinte, com um corpo. Há então dois fatos (simultâneos): eu que me vejo como eu no mais profundo de minha egoidade, e quando vejo que o outro é outro eu, é como eu. Não obstante, Husserl afirma que tal distinção é didática, pois esta percepção compõe um momento único, "apresentação co-apresentativa", que oferece algo que excede ao que eu sou, mas que é como eu! Seria uma percepção que "percebe" (põe) mais do que o "dado em pessoa" ao ego, "percebe" o outro. Autêntica transcendência imanente! (cf. MC 103, e tb. MC 90-91). ${ }^{3}$

A possibilidade de intersubjetividade é também capital para que haja uma experiência autêntica do mundo objetivo. Este supõe "outros não-eu sob a forma de outros-eu". Tal mundo torna-se então "idêntico e uno para cada um", apontando a comunidade de eus, de mônadas, mundo objetivo inerente à subjetividade, (cf. $M C$ 90-91). Os outros não-eu, existindo sob a forma de outros-eu confirmam a minha constituição do mundo: apesar disso, eu não preciso da experiência de outrem para ter a da minha esfera de próprio. Ocorre pois uma "unidade universal" do conjunto do que é constituído no ego (cf. $M C$ 116); o objeto é inferido como unidade intencional intersubjetiva. Surge, desta forma, uma "intencionalidade intersubjetiva transcendental", desvendada por uma "redução intersubjetiva". Confirma-se assim a minha objetividade; e também por isto, "o outro é uma modificação intencional do

3 O Outro à apreendido em mim, é captado da mesma forma que capto a mim próprio em relação ao meu corpo e ao que sou; ele é dado a mim em "carne e osso", porém, não no original. Para isto é preciso então aceitar o outro como uma transcendência imanente ao ego e que não se confundinia com ele. Dito de outro modo, o outro é visto como uma vida corporal que toma sentido, por analogia, a partir de minha vida corporal - a única que posso dispor de modo imediato (cf. $M C$ 80-81). Por uma "associação acoplante" - comparar em forma de casal - inferindo que o outro tem uma vida própria mais que corpo, mais que objeto, chego no entanto a uma igualdade de naturezas. 
meu eu" (MC 97), frase que para muitos resume a falência do projeto husserliano para a alteridade. Eu sou a primeira mônada na qual as outras constituir-se-ão, confirmando minhas sínteses concordantes.

O acoplamento do eu psico-físico do outro com o meu evidencia, automaticamente, o ser comum de uma "Natureza", que servirá de base a qualquer comunidade intersubjetiva, à comunidade das mônadas. As mônadas existem em comunidades e em ligação com o meu ego, elas "existem para mim da mesma forma que eu existo para mim" (MC 109). A intencionalidade implica todo outro; "é o ser que está em comunhão intencional com o ser" (MC 109). Ou seja, a comunidade de mônadas é encontrada em mim mesmo, no âmbito da "intersubjetividade transcendental". Existe assim um único mundo e uma só natureza humana; o cerramento da esfera do solus ipse é, no entanto, também uma abertura a tudo; todo mundo próprio é aberto. O mundo humano é uma "variação eidética de mim mesmo" (MC 119); dá-se na imanência de cada um. Há deste modo uma unidade do mundo objetivo, um só tempo, um só espaço, estruturas "inatas à essência da subjetividade" ( $M C$ 132, cf. tb. $M C$ 119). A existência reciproca de uma para o outro implica uma "assimilação objetivante que coloca o eu e o outro no mesmo plano" (MC 110); e por uma modificação de mim mesmo chego ao ego transcendental em geral, válido para todos (cf. $M C$ 116).

O que se conclui daí? Selada a constituição universal de um mundo comum, a partir do ego monádico, percebe-se que "o outro entra como aquele que confirma a objetividade do ego" constituinte universal e absoluto. Também a intersubjetividade participa no modo "inato à essência da subjetividade. O momento perceptivo bipartido, na apresentação do outro, é ínfimo demais e não transcende de fato à representação do ego.

É possível abordar o outro como "outro eu" e como outro de fato sem restringir sua manifestação às leis perceptivas e cognoscitivas a priori do eu? $\mathrm{O}$ que implica a parte da manifestação e da relação do outro que não se adequa ao modus da razão do cogito? O que implica aquilo que no outro excede à relação de conhecimento e "harmonia das mônadas" num mundo comum? Haverá verdadeira comunicação entre iguais, que participam na mesma razão, tempo e mundo?

Por esta "teoria da participação" toda unicidade e alteridade restam determinadas pelo ego apriorístico, de validade universal, aberto a tudo, apesar de seu cerramento. Aqui, o outro, e o próprio eu, estão absorvidos na objetividade que encarnam; há um sistema enclausurador, determinado por leis egológicas a priori, que dá conta do universo, numa mônada (de modo semelhante ao leibniziano). O projeto de constituição universal tende a reduzir as distâncias entre os interlocutores, a comunicação é dissolvida no campo transcendental dos eus; não há mais que um pensamento, pois uma unidade vem dada por princípio; a comunidade que o ego reúne nao implica, concretamente, em alteridade.

$\mathrm{O}$ anseio por cientificidade, apoditicidade e validade geral levou Husserl, para que seu projeto da egologia não fracassasse, a "determinar a reflexão sobre a alteridade pelo telos da objetividade", o que se torna evidente pela interligação entre comunidade transcendental e mundo objetivo. Constata-se que, por aí, não haveria distinção real entre "intencionalidade do tu" e "intencionalidade do isso". Pela intencionalidade e percepção como tais não se consegue diferenciar um momento que 
respeite a apresentação do outro como outro - em sua grandeza e alteridade invioláveis, como almeja Levinas. O paradoxo da experiência de um "em si" como "para mim" abalar-se-ia quando este em si e é a outra pessoa. As determinações do solipsismo idealista, que abarcam todo sentido possivel na estrutura a priori do cogito, diluem a relação ao outro e "a própria subjetividade do eu".

\section{$2-D_{e}$ Husserl a Levinas, a intencionalidade que se faz ética}

Primeiramente, vemos que Levinas é um fenomenológico, utiliza-se e depende do método, do potencial crítico e das descobertas husserlianas; de igual peso, o faz em vista de um contraponto para a filosofia do Rosto, da prioridade do Outro sobre - Mesmo. Ou seja, mesmo que a partir de Husserl, busca germes de um "mais além", desde quando reflete fenomenologicamente, sobre o modo e o remontar do pensado - o ser que aparece - ao pensamento que o pensa (cf. DVI 232). Levinas precisa deste horizonte, da adequação intencional do vivido, da visão do aparecer e da presença à consciência, para apresentar o outro como Rosto - ao modo de um "superar conservando" - como aquele que tem significação própria, que vai além da manifestação da percepção e da idéia que dele posso inferir (nenhum contexto ou referência o determina). Levinas não deixa de "caminhar às coisas mesmas", ao buscar uma relação ao outro que não comporte violação ética ou redução à universalidade egológica. Todavia, é preciso questionar, para uma autêntica relação ao outro, a modalidade significativa pela qual o próprio sujeito pensante é a origem do sentido, ou seja, a intencionalidade. Diante do outro, é necessário apontar uma verdadeira abertura e transcendência do eu, um momento pelo qual o eu toca a exterioridade. $\mathrm{Na}$ transcendência imanente da consciência intencional o ego não sai do seu eterno retorno do iđêntico sobre si e do seu privilégio lógico e ontológico. Por conseguinte, é preciso, para Levinas, descrever o lugar no qual "o intencional faz-se ética" - a ruptura dos horizontes adequados em vista do momento da visitação do outro. Ele busca uma Sinngebung (dação de sentido) ética, aquém da gnosiológica, que desperte relações sociais autênticas. Vemos que, no privilégio da intencionalidade gnosiológica, ocorre ainda uma correspondência profunda entre psiquismo e pensamento, ser e pensar. Todo sentido é determinado pelo modo do aparecer, pelo acesso aberto pela consciência intencional, pela estrutura a priori que são as leis do ego constituinte. A subjetividade é radicalmente intelecção, eu penso; a inteligibilidade não se transcende, não envia ao mais além de si mesmo diante do outro, do estranho. "A exterioridade do alguma coisa é comandada pela interioridade do sentido" (EDE 14). Todo ultrapassamento resolve-se na imanência, na essencialidade da consciência (cf. $M C 40$ e EDE 130). A racionalidade e inteligibilidade são reduzidas a noemas, à adequação e preenchimento de uma noese, à epoqué, à representação, a uma experiência assimilável - pelo psiquismo como saber. Desta forma, o dado originário do sentido - como o Rosto, por exemplo, momento empírico-ético e intersubjetivo - é moldado em vista do "ser-dado-adequadamente". A adequação e o telos da objetividade captando a alteridade não deixam que se ultrapasse a lógica da intuição, da imanência e da autonomia que se satisfaz no "eu posso" e "eu quero" do ego cogito. O saber é uma satisfação de necessidades, preenchimento de algo já querido e "intuicionado" pela racionalidade do a priori. 
Saber é possuir, transformação do estranho em igual, no que é meu. As desproporções da exterioridade são resolvidas no campo da consciência, que permeia todo espectro do real. A fenomenologia participa assim da periculosidade da filosofia ocidental, onde a relação com o outro não se realiza senão através de um terceiro elemento, neutro e mediador, que encontro em mim mesmo. Onde a autonomia, a liberdade e objetividade do eu conhecedor determinam o sentido da subjetividade e da intersubjetividade, em vista do conceito, em vista do horizonte de compreensão, da forma mentis geral.

Já na posição de Levinas, a presença do Rosto consiste em desnudar-se da forma que contudo o manifesta; o Rosto vem por detrás de sua aparência; é uma abertura na "abertura" do intencional (cf. EDE 194). E é por tudo isso que a diferença entre objetividade e transcendência serve de base a todas as análises da obra TI O que está em jogo aqui á uma nova noção de ipseidade (subjetividade) e de sentido, um deslocamento do significado, na inquietude de um aquém ou além da consciência que não é pensamento, mas que faz sentido. Para Levinas, a autêntica transcendência e transitividade da intencionalidade, diante do outro, será o dobrarse da reflexão ao infinito do outro; será o acolhimento prático do agir ético antes do entendimento que determina o percebido. Saída de si, do egocentrismo, em direção ao outro desejado - sem correlação e sem comunhão intencional no mesmo ser, na presença e na mesma Natureza. Por conseguinte, a socialidade não poderá ter a mesma estrutura do conhecimento; este é ainda uma solidão (cf. EI 62).

\section{3 - Do intencional à subjetividade concreta e sua abertura ao Desejo do Rosto (Visage)}

Se na tradição da filosofia do Mesmo os interlocutores são ordenados sob conceitos, sobre um plano comum e dissolvidos nas relações lógicas captadas em sua generalidade; se a subjetividade é determinada pela razão impessoal, pela própria objetividade e pela totalidade, Levinas começa, para uma autêntica relação com 0 outro, pela descrição de uma subjetividade concreta. É preciso uma separação, respeito ao segredo que é o indivíduo, ponto de partida aquém do que emerge da atividade da consciência, do que é imerso na "ingenuidade apodítica" do científico e na participação e efetivação da razão comum. É preciso, antes, um eu e uma consciência assentados sobre uma exterioridade primeira, num suporte material. Ou seja, é necessário uma interioridade autêntica, vivendo da exterioridade do mundo, pela sensibilidade, gozo, vida eco-nômica. Ressalta-se a vida humana em seu materialismo inicial, voltada para a felicidade e completude. Busca-se descrever uma individuação concreta; o ente humano é autóctone, diz da sensação, afetividade, viver de... (algo), antes que reflexão - a qual deve pressupor tais momentos de pura sensibilidade, contração e constituição do eu, encaminhamento a uma identidade que não é ideal e vazia. O eu vive, precipuamente, como corpo; é encarnado, e isso condiciona o pensamento. É por este viver que aparece o trabalho, que se constrói um lar, para a segurança e aconchego da interioridade, da familiaridade, ao modo do feminino e seu acolhimento. A sensação, o alimento, o gozar a vida, o modo corporal de existir, têm assim uma "função transcendental sui generis"; original conjugação do "em si" e do "para si", da realidade com o indivíduo, sem o apor- 
te do eu puro ideal por trás. É uma transcendência pela qual o eu sai de si (vai ao mundo material, usufrui, vive...) e retorna a si pleno e cumulado, concretamente. Somente com tal transcendência primordial, mesmo que redutível, é que o eu pode abrir-se para a transcendência irredutivel, relacionar-se com o que lhe falta, com o que é maior e que não pode ser abarcado ou "consumido", isto sem diluir-se ou diluir este infinito numa totalidade pois os entes já estão constituídos concretamente ("a sensação destrói todo sistema" - TI 30). Esta saída de si, na relação com o que não se pode assimilar, é possivel com a visitação do Rosto que abre a dimensão do infinito, ou seja, desperta o Desejo do Outro, uma "necessidade" que é mais que necessidade, que nunca se completa ou satisfaz. Somente aqui o eu distingue 0 material do espiritual (cf. TI 89-90). Tal relação é descrita, teórica e formalmente, como a idéia do infinito que vem ao finito. Mas uma idéia sem correlação; seu ideado, sua intenção é outrem, ultrapassa a própria idéia; diz da exterioridade tocando a interioridade. É o esquema teórico da relação social em que se respeita o ser conhecido, relação meta-física. O eu contém mais do que o seu pensamento intui. Mas como um pensamento pode almejar mais do que o pensado? Este desinstalar e inadequação, mais no menos, fazer mais e melhor que pensar, realiza-se, concretamente, como Desejo do Outro, o qual se manifestou como Rosto - em que se pressente a "presença" enigmática do infinito. Com o Desejo é despertada uma outra modalidade do humano. Se no mundo de necessidades temos um eu que goza e faz do saber um poder, com o desejo temos um psiquismo que não se contém, que sente seu egocentrismo extrapolar-se; abala-se aqui sua idealidade e completude, pois agora ele está direcionado à alteridade. Ultrapassamento da complacência animal, esvaziamento do pólo e do peso egológico, "situação" que confirmará a grandeza, a altura e a bondade do humano. O Desejo é um choque, um traumatismo, uma afecção no mais profundo da subjetividade. É uma atração abismal que puxa o eu para além do que o faz saber-se como eu, para além de sua atividade de identificação na "propriedade do próprio". O Desejo abre um mundo que se faz (que pode fazer-se) bondade, para além das lutas e posses encarniçadas dos indivíduos e das "tribos" sociais; é acolhimento da alteridade do Outro, que é maior e me precede. Entretanto, a afecção profunda que é o Desejo, este sentimento primordial, não surge senão quando despertado pelo outro como Rosto, completamente exterior, o qual quebra a lógica do meu pensamento e totalização. O Rosto é o "modo como o outro se apresenta ultrapassando a idéia que tenho dele"; ele tem sentido próprio. Pode revelar tanto a altura daquele que me ensina - pois é exterior e mais do que o meu pensar - quanto a miséria, nudez e vulnerabilidade que chocam. O Rosto questiona os lugares e a prioridade do "para mim', questiona a minha posse e o meu saber irresponsável. Despossuído e nu, escapa a generalidades, à espécie, à queda em uma totalidade. O imperativo primeiro do Rosto - interdição nos meus poderes, resistência ética - é o "tu não matarás", que é o seu logos, que é o respeito à vida acima de tudo, ao que não me pertence. A resposta à demanda do rosto, o caminhar ao encontro do que atrai abismalmente e nunca é aplacado, a viabilização da relação vem como discurso. O discurso ou palavra, é assentado neste face a face original, é o acolhimento da expressão do outro que é imediatamente interpelação e que exige resposta (res-ponsabilidade). Semelhante resposta é continua, não aplaca a vontade e não realiza uma liberdade. Antes do des- 
velamento de qualquer fenômeno, antes de qualquer adequação à visão e ao entendimento, o Rosto fala, não se deixa coagular nos fins e utilidades da linguagem e na sua racionalidade estabelecida e estanque. Ele, antes, assegura e assiste sua presença, que é também uma ausência; defende-se da fixação e conformação ao meu esquema mental, retórico, comercial e interesseiro - palavra em prol de si mesmo. Deste modo, o sentido primeiro de todo saber e comunicação, o que justifica a ação da consciência e a constituição do mundo, é o Outro como Rosto; uma situação inter-humana radical anima assim o fundamento do teorético; situação que condiciona o pensamento racional, eleva o humano para além do egoísmo e da barbárie. Instaura-se a comunicação entre seres assimétricos, sem a decaída na razão impessoal; seres que são pessoas, que podem se relacionar no desejo e no discurso; pessoas, capazes de servir umas as outras, sem diluirem-se no grupo; por conseguinte, uma possibilidade de construir a paz.

\section{Bibliografia}

HUSSERL, Edmund. Méditations Cartésiennes. Paris: J. Vrin (tradução de E. Levinas e G. Peiffer), 1969. (MC)

LEVINAS, Emmanuel. Totalité et Infini. La Haye: Martinus Nijhoff, 1971. (TI)

—_ En Découvrant l'Existence avec Husserl et Heidegger, Paris: J. Vrin, 1970. (EDE)

. Ethique et Infini. Entrevista com F. Nemo. Paris: Fayard, 1982. (EI)

. Humanismo do Outro Homem. Petrópolis: Vozes, 1993 (tradução do Grupo de Estudos sobre E. Levinas da PUCRS).

. De Dieu qui Vient a l'Idée. Paris: J. Vrin, 1986.

PELIZZOLI, Marcelo L. A Relação ao Outro em Husserl e Levinas. Porto Alegre: EDIPUCRS, 1994. 